PKS REVISTA ENSINO DE GEOGRAFIA OJS

PUBLIC

KNOWLEDGE

(RECIFE)

OPEN

PROJECT

http://www.revista.ufpe.br/ensinodegeografia

JOURNAL SYSTEMS

\title{
A PESQUISA COMO ESPAÇO DE REFLEXÃO NA FORMAÇÃO DE PROFESSORES DE GEOGRAFIA
}

\author{
Valdemira Pereira Canêjo de Andrade \\ Mestranda do Programa de Pós-graduação da UFPE \\ valcanejo21@gmail.com \\ Dr. Francisco Kennedy Silva dos Santos \\ Universidade Federal de Pernambuco (UFPE) \\ kennedyufpe@gmail.com
}

\begin{abstract}
RESUMO: Na formação de professores de Geografia introduzir a pesquisa como princípio intelectual e formativo é enriquecedor, uma formação que transcenda os limites das universidades, devendo permitir uma articulação entre pesquisa, formação acadêmica e o campo de atuação profissional, que é a realidade escolar. Dessa forma, o desafio dessa investigação é compreender a pesquisa como princípio educativo na formação de professores de Geografia e o seu papel como fator relevante para com o campo de atuação profissional. Portanto, na tessitura da ação metodológica optou-se pela pesquisa qualitativa de cunho bibliográfico, realizando um aprofundamento teórico e documental, na tentativa de discutir com os autores a temática em tela. Neste intuito, a pesquisa é relevante na formação de professores de Geografia, possibilitando ser um profissional, investigador, reflexivo e questionador da área e que possam refletir como se movem os saberes pedagógicos e da ação pedagógica na prática, entretanto, no diálogo entre teoriaprática.
\end{abstract}

Palavras-chave: Formação de professores de Geografia, Ensino-pesquisa, Campo de atuação profissional.

\section{RESEARCH AS A SPACE FOR REFLECTION IN THE FORMATION OF GEOGRAPHY TEACHERS}

\begin{abstract}
In the formation of Geography, introducing research as an intellectual and formative principle is enriching. It is a formation that transcends the bounders of the universities, and allow an articulation between research, academic formation and the field of professional activity, where it is the school reality. Thus, the challenge of this research is to understand it as an educational principle in the formation of Geography teachers and its function as a relevant factor in the field of professional activity. Therefore, in the context of methodological action, we choose for the qualitative research a work based on bibliographic, theories and documentaries to discuss the subject with the authors. In this context, research is relevant to the formation of Geography teachers, and allow to be a
\end{abstract}


professional, researcher, reflective and thinker about the subject which they will be able to reflect about how pedagogical knowledge and pedagogical action move in practice and in dialogue between theory and practice.

Keywords: Formation of Geography teachers, Teaching-research, Field of professional activity.

\section{INICIANDO A DISCUSSÃO}

Os caminhos da pesquisa na formação de professores como princípio intelectual e formativo são elementos fundamentais para a criação de percepções que gerem possibilidades para a formação e a prática pedagógica do professor. Para tanto, os cursos de Geografia, em nível de graduação, tanto da licenciatura como o do bacharelado, há a possibilidade de pesquisar durante o processo de formação inicial, ou seja, não é apenas o bacharel que é formado como pesquisador, o licenciado também é um pesquisador e seu objeto de pesquisa é o ensino, tornando-o profissional planejador e investigador da prática, como ressalta a proposta delineada nas Diretrizes para a Formação de Professores da Educação Básica, em cursos de nível superior (BRASIL, 2001, p. 35): “[...] o foco principal do ensino da pesquisa nos cursos de formação docente é o próprio processo de ensino e de aprendizagem dos conteúdos escolares na educação básica”.

Neste sentido, atualmente ainda prevalecem algumas ideias preconcebidas que a pesquisa só é concebida ao pesquisador, mas especificamente o doutorado e na universidade que adquire habilidades para efetiva-la. Diante dessas questões, podemos perceber que este quadro se reverteu e que a pesquisa é primordial para com o processo de formação de professores, possibilitando uma investigação crítica e reflexiva da profissão. (ABU-EL-HAJ; LEITINHO; CARDOSO, 2013). Portanto, é necessário ressaltar, que não só no doutorado é concebida a pesquisa, mas em outras instâncias formativas e níveis de complexidade diferentes. Podemos destacar o PIBIC, TCC, especialização etc.

Partindo deste pressuposto, a efetividade da pesquisa na formação de professores de Geografia dará respostas na atuação profissional. Diante disso, surgem algumas inquietações iniciais: Por que pesquisar na formação inicial? Que objeto de estudo é investigado pelos licenciandos de Geografia durante a formação inicial e relação para com o campo de atuação profissional? Não estamos falando apenas da pesquisa 
relacionada aos saberes disciplinares (conhecimento científico), mas dos saberes pedagógicos e da ação pedagógica desenvolvida na sala de aula.

Neste contexto, a pesquisa na formação inicial vem se tornando um dos desafios para alunos dos cursos de licenciatura, ser um profissional criativo, autônomo e um pesquisador, em especial com a realidade dos alunos não é fácil, requer uma formação diferenciada e fazer de sua área de atuação um objeto de investigação. O objeto de investigação do professor em formação é o cotidiano e a realidade da escola, entretanto, não é o que frequentemente acontece. Não acorre, pois, de modo geral, o que se reverbera como pesquisa durante a formação, não só em Geografia, mas em outras áreas de formação, é a pesquisa que investiga saberes disciplinares (conhecimento científico), rejeitando investigações sobre como são produzidos e como se movem os saberes pedagógicos e da ação pedagógica na prática. Além disso, há um espaço diminuto para a produção destas pesquisas dos saberes pedagógicos, em detrimento de outras que possuem espaço físico e epistêmico maior.

As reflexões, aqui apresentadas, são resultados de um estudo de investigação que tem como objetivo compreender a pesquisa como princípio educativo na formação de professores de Geografia e o seu papel como fator relevante para com o campo de atuação profissional. Portanto, na tessitura da ação metodológica optou-se pela pesquisa qualitativa de cunho bibliográfico, visto que o fenômeno aqui apresentado dificilmente pode ser quantificado (MINAYO, 2009), realizando um aprofundamento teórico e documental, na tentativa de discutir com os autores a temática em tela.

A inserção da pesquisa na formação de professores tem se tornado primordial nos cursos de graduação e na prática do professor. A pesquisa como parte integrante da formação no curso de licenciatura de Geografia possibilitará formar bons professores, capazes de questionar e problematizar criticamente sobre o ensino e o contexto social de sua realização, refletir sobre os procedimentos metodológicos e linguagens a serem utilizadas em sala de aula, ou seja, como afirma Pontuschka; Paganelli; Cacete (2009, p. 28), "Um curso de formação que tenha como princípio orientador a pesquisa e se preocupe com os métodos, técnicas e linguagens a serem utilizadas no ensino de Geografia terá condições de formar um bom professor dessa disciplina”.

Não se fala de uma formação voltada apenas para a sala de aula, mas numa perspectiva em que os licenciandos tenham em mente seu objeto de estudo, sujeitos e campo de atuação profissional, concordando com Sampaio e Vlach $(2008$, p. 53) “[...] seu 
Revista Ensino de Geografia (Recife), v. 1, n. 1, mai./ago. 2018
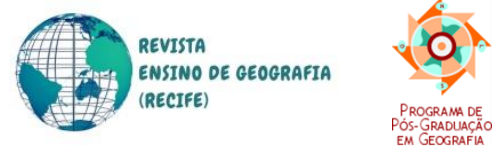

objeto de pesquisa é também o sujeito, assim como ele mesmo: um sujeito construindo a sua história e transformando o seu espaço". E que seja capaz de exercer papel de um pesquisador - professor investigador da área.

Pesquisar possibilita compreender o mundo, onde o sujeito, enquanto ser inacabado e inconcluso busca respostas para as inquietações sobre esse mesmo mundo. Pesquisar é princípio fundamental de aprendizagem e interação com outros sujeitos e objeto. É, para além de uma racionalidade técnica, transitar a uma comunicação dialógica e construtiva.

\section{O PAPEL DA PESQUISA NA FORMAÇÃO DE PROFESSORES DE GEOGRAFIA}

Ensinar a pesquisar requer criar situações $e$ condições didáticas que estimulem a curiosidade e a criatividade. (PONTUSCHKA; PAGANELLI; CACETE, p. 98, 2009).

A pesquisa é enriquecedora para a formação dos professores e se torna mais importante e necessária quando contribui a prática desenvolvida pelo professor, pesquisar para compreender e refletir sobre as condições do espaço escolar, possibilitando diálogo entre pesquisa, formação e prática profissional. Como ressalta Coltrinari (2006, p. 115) "Pesquisa é a procura, ou indagação cuidadosa e sistemática, realizada com a finalidade de descobrir ou estabelecer fatos ou princípios relativos a um campo qualquer de conhecimento".

A pesquisa é fundamental no processo de formação do futuro professor, seja em sua formação inicial assim como continuada, possibilitando um espaço para que os profissionais de exercício possam refletir e se posicionar de forma crítica, despertando nos sujeitos atitude autônoma. Como ressalta Ludke (2001, p. 51), “[...] é necessário introduzir o futuro professor no universo da pesquisa, em sua formação inicial e também continuada, garantindo assim a possibilidade de exercício do magistério de maneira muito mais crítica e autônoma". Neste sentido, possibilitando um espírito investigador, um profissional crítico-reflexivo, inacabados em busca do ser mais e responder questionamentos encontrados no caminho da formação e no exercício e contribuir para um processo de atitude de emancipação e autonomia do profissional. 
Tais reflexões nos levam a compreender a importância da pesquisa na formação de professores. É importante ressaltar que a formação dos licenciandos vai além dos muros da universidade, não apenas formar o professor para ensinar um conteúdo ou qualifica-lo numa área especifica, mas um professor-investigador reflexivo, o qual identifique os problemas e problemáticas emergentes no 'chão da escola', levantando hipóteses e elaborando soluções que sirvam de roteiro de mudança. Como salienta Soares (2001, p. 93), "Formar o professor não é apenas qualificá-lo em uma "área específica", capacitá-lo teórica e metodologicamente para ensinar determinado conteúdo, mas é também formá-lo para enfrentar e construir a ação educativa escolar em sua totalidade".

Pesquisar na formação inicial propiciará encontrar respostas no exercício da profissão. Com isso, é necessário que os futuros profissionais, em seu processo de formação inicial, pesquisem para que reflitam como são praticados os conhecimentos por eles ensinados. (PONTUSCHKA; PAGANELLI; CACETE, 2009).

Por meio da presente Resolução (BRASIL, 2015) define as Diretrizes Curriculares Nacionais para a formação inicial em nível superior - cursos de licenciatura, cursos de formação pedagógica para graduados e cursos de segunda licenciatura e para a formação continuada, assim ressalta, a pesquisa além de constituir-se como instrumento de ensino é um conteúdo na construção da aprendizagem na formação profissional do professor. Oportuniza analisar e retratar o contexto escolar permitindo ao professor ultrapassar os muros da escola, refletir criticamente todo o processo de construção, que é o conhecimento e a vida dos alunos, e está pronto para as situações que se depara no ambiente escolar, e problematizar para com a realidade da profissão.

Muitas universidades avançaram no campo da pesquisa. As políticas de fomento fazem parte deste avanço, a partir da década de 1970. Entre os primeiros modelos, destacamos o Conselho Nacional de Desenvolvimento Científico e Tecnológico (CNPQ) e outros órgãos públicos de incentivo à pesquisa, bem como, Coordenação de Aperfeiçoamento de Pessoal de Nível Superior (CAPES), nas linhas de ação, vem contribuindo ao fomento da formação inicial e continuada de professores para a educação básica (SAMPAIO; VLACH, 2008). Na formação inicial, as políticas de fomento têm estimulado e influenciado a formação profissional a prática da pesquisa, tal como, participação dos licenciandos em programa de iniciação cientifica.

Neste intuito, ser um profissional investigador, reflexivo e questionador da área, ultrapassa os muros da universidade. Não é apenas fazer uma graduação, cursar as 
disciplinas, copiando fichas e anotações de aula, mas ir além do que lhe é exigido. Construir seu próprio conhecimento, elaborar pesquisas que movimente os saberes apreendidos no processo formativo. É problematizar, a partir do exame sobre a prática educativa, os saberes que estão na base de sua área de formação.

No entanto, os professores devem ser profissionais críticos e reflexivos, especialmente os que trabalham com a Geografia. Por isso, é importante a construção de múltiplos saberes, para dialogarmos com os textos acadêmicos e as experiências do fazer/ser docente, na busca para construímos um profissional investigador. A pesquisa é princípio fundamental na formação de professores de Geografia, bem como para os profissionais que já atuam na educação, movimentando os textos científicos e contextualizando para com a atividade profissional.

Neste movimento de discussão, percebe-se o quão a pesquisa é importante e necessária na formação inicial, para não recairmos na reprodução do saber e receber as informações sem questionar. Pesquisar para entender e refletir a prática docente; os caminhos da profissão e a própria escola, nosso lugar de atuação. A prática cotidiana do professor é o ponto de questionamento, problematização, cabe ao professor investiga-la para encontrar os problemas que pareciam estar organizados e conforme o contexto real da escola. A pesquisa é o momento de duvidar das certezas apresentadas no campo profissional. Assim, não existem conteúdos de ensino prontos e acabados, é necessário pesquisar-procurar para ensinar. De acordo com Corazza (2002, p.57), ao “[...] problematizar o que não era nenhum problema, nem problemático, para as outras formas de ensinar e de pesquisar, fazemos a pesquisa-que-procura e ensina”.

Pesquisar na formação inicial para não tornar-se repetidor de conteúdos, mas um professor pesquisador, curioso e criativo para com a profissão. Como já afirma Cavalcanti (2008, p. 53) "O professor deve ser necessariamente um pesquisador. E se ele não pesquisar, deixará de ser professor e passará à categoria de mero repetidor de conteúdos”. Repetir; decorar conteúdos; aulas autocráticas, centradas no professor e os alunos ouvir e copiar já não é possível na sala de aula e para com a construção do conhecimento.

Considerando estas reflexões, pesquisar tem por condição o exercício da curiosidade, da criatividade, do descobrimento. Na formação inicial descobrir o que parece algo que não estar claro nas nossas leituras, partindo do questionamento. Pesquisar e estudar para saber e mudar/atuar na profissão. (DEMO, 2006). 
A pesquisa durante o processo formativo no ensino de Geografia ajudará aos futuros professores recriar as aulas, dar sentido e significado a aprendizagem e permitir ter acesso a várias metodologias. Como aponta Pontuschka; Paganelli; Cacete (p.99, 2009):

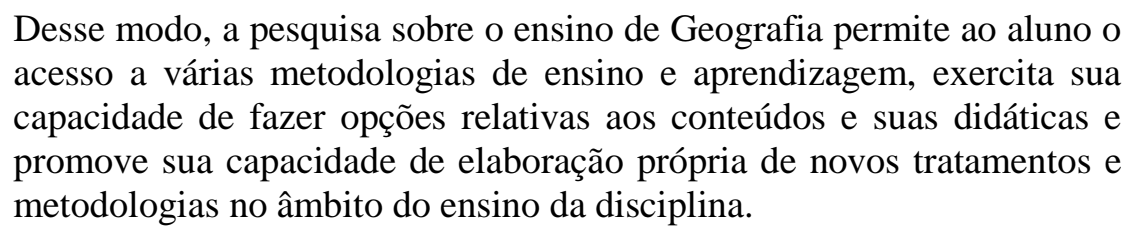

Neste contexto, pensando na importância da pesquisa como princípio educativo na formação de professores, podemos perceber que nem todos os licenciandos percorrem os caminhos da pesquisa. Não é apenas pesquisar, mas relacionar, usar os resultados em beneficio da comunidade escolar e criticar situações presentes no trajeto educativo. Sabese que não é fácil investigar, mas quando não ocorre a pesquisa na formação, seja ela inicial ou continuada, as dificuldades ficarão mais claras no exercício da profissão, o não questionar da prática, terá menos recursos para indagar, com isso, é necessário introduzir a pesquisa na formação, tornando um profissional investigador de atitude autônoma e crítico para com o contexto e realidade no qual se insere. $\mathrm{Na}$ linha de pensamento de Ludke (2001, p. 51),

[...] é necessário introduzir o futuro professor no universo da pesquisa, em sua formação inicial e continuada, garantindo assim a possibilidade de exercício do magistério de maneira muito mais crítica e autônoma. O futuro professor que não tiver acesso à formação e à prática de pesquisa terá, a meu ver, menos recursos para questionar devidamente sua prática e todo o contexto no qual ela se insere, o que o levaria em direção a uma profissionalidade autônoma e responsável.

Pesquisar para refletir, criar e descobrir vai além de um levantamento bibliográfico. Este é um aspecto presente e que retrata o pensamento de alguns alunos da graduação. A pesquisa é compreendida como levantamento bibliográfico, reunir várias informações, sem que estas sejam questionadas, problematizadas. Além disso, a dificuldade que os alunos têm, é discernir a coleta de dados, distinguir e relacionar as informações levantadas, com foco na pesquisa. O problema da questão central da pesquisa não é analisado e interrogado nas leituras e fontes consultadas pelos alunos. (ABU-EL-HAJ; LEITINHO; CARDOSO, 2013). É desafiador na formação inicial para alguns alunos compreender, ter clareza e domínio dos elementos constituintes que definem uma pesquisa na academia e que seja contemplada para com a área de formação. 
Estar inserido no mundo da pesquisa, contextualizando e relacionando com objeto de formação, ultrapassa as disciplinas ofertadas no currículo, envolve todo conjunto de disciplinas e atividades complementares para com o processo formativo. Investigar é importante e necessário na formação inicial, possibilitando ao sujeito-aluno e sujeitoprofessor ser capaz de identificar as potencialidades e limitações presentes no ato da profissão. No processo de formação no curso de licenciatura nem todos os graduandos percorrem a prática da pesquisa, de acordo Sampaio e Vlach (2008, p.59) “[...] a maioria dos alunos que cursam a graduação só tem acesso à pesquisa de iniciação científica no momento da monografia". Sejam por falta de interesse, dificuldades em entender qual o objeto e objetivo da pesquisa ou ausência de oportunidades durante os anos do processo formativo inicial.

Outras dificuldades dos graduandos diante da natureza do conhecimento, ou seja, a experiência do ensino com pesquisa na graduação é que os alunos ingressantes trazem para a universidade uma bagagem do senso comum, sem amadurecimento científico. Tal comportamento adquirido na educação básica e, ainda presente no ensino superior é que a ele não compete problematizar ou questionar, pesquisar, mas apenas memorizar. Diante disso, é enfatizado que durante a formação é necessário conduzir o aluno a observar o dia a dia, levando-o a articular o senso comum ao conhecimento científico, possibilitando ampliar os olhares dos alunos para com a realidade social. (ABU-EL- HAJ; LEITINHO; CARDOSO, 2013).

Neste patamar, é importante salientar que o licenciando desde a formação inicial, adquira e aprenda conhecimentos que contribua na compreensão do ensino como realidade social. Para isso, é essencial instrumentos que lhe capacitem investigar, possibilitando para que caminhe da transmissão para a investigação, capazes de refletir criticamente sobre o ensino e entenda o meio cultural de seus alunos, indissociável das transformações do mundo (SAMPAIO; VLACH, 2008).

\section{PALAVRAS FINAIS}

É importante que a atividade de pesquisa, enquanto mediação do processo de formação, aproxime o futuro professor de Geografia da realidade escolar e de seu campo de atuação profissional. Para que isso se realize, entretanto, é necessário que as disciplinas e atividades do curso insiram a pesquisa no processo de formação inicial, possibilitando, assim, a articulação entre ensino e pesquisa, promovendo aos futuros 
professores que analisem, questionem e reflitam criticamente sobre o cotidiano da escola e o contexto social de sua realização.

Durante a formação inicial, os licenciandos de Geografia têm oportunidade de participar da pesquisa, seja na Iniciação Científica que é uma modalidade de pesquisa em que os alunos da graduação são iniciados na prática científica e estimulados a participar de projetos de pesquisa desenvolvidos na Universidade e reafirma a vocação para a pesquisa da Universidade e garante que ela tenha continuidade no futuro. O Programa Institucional de Bolsas de Iniciação à Docência - PIBID que incentiva e contribui na formação de professores e valorização do magistério, bem como a participação desses licenciandos nos laboratórios ou grupos de pesquisa, onde são trabalhados e discutidos temas que contribuem na formação dos licenciandos, além disso, oportunidades de participar de projetos de extensão que evolva a comunidade, escola, tendo ação-reflexãoação das pesquisas elaboradas.

Aproximar os alunos durante a formação inicial a pesquisa é enriquecedor, entretanto, temos alguns casos que os licenciandos não têm oportunidade de participar de Iniciação Cientifica; Iniciação à Docência; projetos de extensão e laboratórios ou grupos de pesquisa, mas não significa que os futuros professores não será um bom profissional, durante as disciplinas ofertadas na graduação os alunos poderá investigar os saberes disciplinares (conhecimento científico) dialogando sobre como são produzidos e como se movem os saberes pedagógicos e da ação pedagógica, possibilitando diálogo para uma práxis (teoria-prática).

\section{REFERÊNCIAS}

ABU-EL-HAL, Mônica; LEITINHO, Meirecele Calíope; CARDOSO, Nilson de Souza. O ensino com pesquisa: contextualização e reflexões metodológicas. In: FARIAS, Isabel Maria Sabino; THERRIEN, Silvia Maria Nóbrega; CARVALHO, Antonia Dalva França. Diálogos sobre a formação de professores: olhares plurais. Teresina/PI: EDUFPI, 2013.

BRASIL. Parecer CNE/CES n. ${ }^{\circ}$ 492, de 3 de abril de 2001. Aprova as Diretrizes Curriculares Nacionais dos cursos de Arquivologia, Biblioteconomia, Ciências Sociais - Antropologia, Ciência Política e Sociologia, Comunicação Social, Filosofia, Geografia, História, Letras, Museologia e Serviço Social. Conselho Nacional de Educação. Brasília: Conselho Nacional de Educação, 2001.

RESOLUÇÃO $\mathrm{N}^{\circ}$ 2, DE $1^{\circ}$ DE JULHO DE 2015. Define as Diretrizes Curriculares Nacionais para a formação inicial em nível superior (cursos de 
licenciatura, cursos de formação pedagógica para graduados e cursos de segunda licenciatura) e para a formação continuada. Brasília: Conselho Nacional de Educação, 2015.

CAVALCANTI, Lana. Formação inicial e continuada em Geografia: trabalho pedagógico, metodologias e (re) construção do conhecimento. In: ZANATTA, Beatriz Aparecida; SOUZA, Vanilton Camilo de. Formação de professores: reflexões do atual cenário sobre o ensino da Geografia. Goiânia: Vieira. 2008.

COLTRINARI, L. A pesquisa acadêmica, a pesquisa didática e a formação do professor de geografia. In: PONTUSCHKA, N. N.; OLIVEIRA, O. U. Geografia em perspectiva: ensino e pesquisa. São Paulo: Contexto, 2006.

CORAZZA, Sandra Mara. Pesquisa-ensino: o "hífen" da ligação necessária na formação docente. In: ESTEBAN, Maria Tereza; ZACCUR, Edwiges. Professora Pesquisadorauma práxis em construção. Rio de Janeiro: DP\&amp;A, 2002.

DEMO, Pedro. Pesquisa: princípio científico e educativo. 12. ed. São Paulo: Cortez, 2006.

LUDKE, Menga. A complexa relação entre o professor e a pesquisa. In: ANDRÉ, M. O papel da pesquisa na formação e na prática dos professores. Campinas- SP: Papirus, 2001.

MINAYO, S. C. M. (Org) Pesquisa Social: teoria, método e criatividade. Petrópolis-RJ: Vozes, 2009.

PONTUSCHKA, N. N.; PAGANELli, Tomoko lyda; CACETE, Núria Hanglei. Para ensinar e aprender Geografia. $3^{\text {a }}$ ed. São Paulo: Cortez, 2009.

SAMPAIO, Adriany de Ávila Melo; VLACH, Vânia Rúbia Farias. Concepções teóricas e pesquisa no ensino de geografia. In: ZANATTA, Beatriz Aparecida; SOUZA, Vanilton Camilo de. Formação de professores: reflexões do atual cenário sobre o ensino da Geografia. Goiânia: Vieira. 2008.

SOARES, Magda. As pesquisas nas áreas específicas influenciando o curso de formação de professores. In: ANDRÉ, M. O papel da pesquisa na formação e na prática dos professores. Campinas- SP: Papirus, 2001. 